\title{
Solute Transport through a Pine Bark-based Substrate under Saturated and Unsaturated Conditions
}

\author{
Tyler C. Hoskins ${ }^{1}$, James S. Owen, Jr. ${ }^{2,4}$, and Jeb S. Fields ${ }^{1}$ \\ Department of Horticulture, Virginia Tech, Hampton Roads Agricultural Research and Extension \\ Center, Virginia Beach, VA 23455
}

James E. Altland

USDA-ARS, Application Technology Research Unit, 27 Horticultural Insects Research Laboratory, Wooster, OH 44691

Zachary M. Easton ${ }^{2}$

Department of Biological Systems Engineering, 205 Seitz Hall, Blacksburg, VA 24061

\author{
Alex X. Niemiera ${ }^{3}$ \\ Department of Horticulture, Virginia Tech, 301 Saunders Hall, Blacksburg, VA 24061
}

AdDiTIONAL INDEX wORDs. breakthrough curve, cation exchange capacity, containerized crops, nitrate, phosphate, potassium

\begin{abstract}
An understanding of how dissolved mineral nutrient ions (solutes) move through pine bark substrates during the application of irrigation water is vital to better understand nutrient transport and leaching from containerized crops during an irrigation event. However, current theories on solute transport processes in soilless systems are largely based on research in mineral soils and thus do not necessarily explain solute transport in soilless substrates. A study was conducted to characterize solute transport through a 9 pine bark:1 sand (by volume) substrate by developing and analyzing breakthrough curves (BTCs). Columns filled with pine bark substrate were subjected to the application of a nutrient solution (tracer) and deionized water under saturated and unsaturated conditions. Effluent drained from the columns during these applications was collected and analyzed to determine the effluent concentration $(\mathrm{C})$ of the bulk ions in solution through electrical conductivity $(\mathrm{EC})$ and nitrate $\left(\mathrm{NO}_{3}{ }^{-}\right)$, phosphate, and potassium $\left(\mathrm{K}^{+}\right)$concentrations. The BTCs were developed by plotting $\mathrm{C}$ relative to the concentration of the input solution $\left(C_{0}\right)$ (i.e., relative concentration $\left.=C / C_{0}\right)$ as a function of the cumulative effluent volume. Solutes broke through the column earlier (i.e., with less cumulative effluent) and the transition from $C / C_{0}=0$ to 1 occurred more abruptly under unsaturated than saturated conditions. Movement of the anion, $\mathrm{NO}_{3}^{-}$, through the substrate was observed to occur more quickly than the cation $\mathrm{K}^{+}$. Throughout the experiment, $37 \%$ of the applied $\mathrm{K}^{+}$was retained by the pine bark. The adsorption of $\mathrm{K}^{+}$to pine bark cation exchange sites displaced calcium $\left(\mathrm{Ca}^{2+}\right)$ and magnesium $\left(\mathrm{Mg}^{2+}\right)$, of which the combined equivalent charge accounted for $43.1 \%$ of the retained $\mathrm{K}^{+}$. These results demonstrate the relative ease that negatively charged fertilizer ions could move through a pine bark substrate while solution is actively flowing through substrate pores such as during irrigation events. This approach to evaluating solute transport may be used in horticultural research to better understand how mineral nutrients move through and subsequently leach from soilless substrates during irrigation. Expanding this knowledge base may lead to the refinement of production practices that improve nutrient and water use efficiency in container nurseries.
\end{abstract}

Pine bark is a widely used substrate component in the southeastern and mid-Atlantic regions of the U.S. nursery industry for the production of container-grown, woody ornamental

Received for publication 4 June 2014. Accepted for publication 29 Aug. 2014 This publication is a portion of a thesis submitted by Tyler C. Hoskins in partial fulfillment of the degree of Master of Science.

Partial funding was provided by the Virginia Nursery and Landscape Association. Funding for this work was provided in part by the Virginia Agriculture Experiment Station and the Hatch program of the National Institute of Food and Agriculture, U.S. Department of Agriculture.

Special thanks to Julie Brindley for technical assistance and Drs. Michelle Frey and Ryan Stewart for input and guidance.

Trade or brand names used in this publication do not constitute a guarantee or warranty of the product by Virginia Tech and do not imply its approval to the exclusion of other products or vendors that also may be suitable.

${ }^{1}$ Graduate Research Assistant.

${ }^{2}$ Assistant Professor.

${ }^{3}$ Professor.

${ }^{4}$ Corresponding author. E-mail: jim.owen@vt.edu. crops. As a result of the high porosity and relatively low waterholding capacity of pine bark-based substrates, frequent irrigation is required to supply adequate water to the crop. During irrigation, the unwanted leaching of water and applied mineral nutrients is a common occurrence. An understanding of how dissolved mineral nutrients (i.e., solutes) move through pine bark substrates is fundamental to reducing the quantity of fertilizers leached from nursery containers during irrigation. Significant effort has been placed on understanding the leaching of mineral nutrients from soilless substrates on a large time scale (i.e., throughout a production season; $\approx 4$ to 12 months) in systems where controlled-release fertilizers (CRFs), a currently recommended best management practice (Bilderback et al., 2013), are used as the nutrient delivery method (Alam et al., 2009; Cabrera, 1997, Colangelo and Brand, 2001; Cox, 1993; Newman et al., 2006).

The rate at which mineral nutrients are released from CRFs is often cited to be influenced largely by temperature (Adams 
et al., 2013; Husby et al., 2003), and subsequently, temperature is used as a partial predictor of the quantity of nutrients released into the substrate solution that may leach during irrigation. However, a more complete estimation of the actual nutrient load that is leached during irrigation or rainfall would be accomplished by considering not only the quantity of available nutrients in the substrate solution, but also the intensity of irrigation or precipitation and the physiochemical properties of the substrate. Expanding our knowledge of the physiochemical factors that affect solute transport during irrigation may allow practitioners to better manage applied nutrients and provide data to help improve recent crop management models (Majsztrik, 2011) to better predict fertilizer use efficiency.

Research on how water and solutes move through mineral soil systems (Beven and Germann, 2013; Keller et al., 2004; Liu et al., 2010; Mohammadi et al., 2009) provides a foundation on which current theories of solute transport in soilless substrates are built. However, soilless substrates, which are predominantly made of organic matter, possess different physiochemical properties than mineral soils, including high porosity $[\approx 75 \%$ total porosity $(\mathrm{TP})$ for the pine bark/sand blend used in this study], low bulk density $\left(D_{b}\right)$, low ion exchange capacity, and low surface area. Because of these differences between soils and soilless substrates, an independent body of research on solute transport through pine bark substrates is warranted to best manage mineral nutrient leaching during irrigation. Hoskins (2014) began this process by evaluating the flow of applied irrigation water through a pine bark substrate and demonstrated the tendency for water to preferentially flow through certain portions of the substrate, a process that is dependent on substrate moisture content. However, there is limited information that bridges the gap between our understanding of solute transport in soilless substrates and that of soils.

Brown and Pokorny (1977) reported that soluble potassium applied to the top of a pine bark-filled column resulted in $\mathrm{K}^{+}$ adsorption to the bark and that the distribution of that adsorbed $\mathrm{K}^{+}$was uneven throughout the column with most retained in the upper portion of the substrate profile. Furthermore, they demonstrated that an increase in $\mathrm{pH}$ led to an increase in the amount of adsorbed $\mathrm{K}^{+}$, indicating the presence of $\mathrm{pH}$ dependent functional groups, which has been confirmed in several subsequent studies (Daniels and Wright, 1988; Foster et al., 1983). Foster et al. (1983) applied deionized (DI) water to pine bark-filled columns that had been pre-treated with a ammonium nitrate $\left(\mathrm{NH}_{4} \mathrm{NO}_{3}\right)$ solution and found that the majority of both ammonium $\left(\mathrm{NH}_{4}{ }^{+}\right)$and nitrate ions were leached with $120 \mathrm{~mL}$ of DI water, which was slightly less than the total column volume $(170 \mathrm{~mL})$. With the exception of Brown and Pokorny (1977), no other studies solely focused on anion or cation transport in soilless substrates or reported complete substrate physical properties, making interpretation and comparison against other studies difficult.

Breakthrough curve analysis can provide valuable information about the physiochemical properties of the substrates used in containerized plant production and how they affect solute transport during irrigation. A BTC is a plot of the relative effluent solute concentration vs. time or cumulative discharge (Hillel, 2004). To conduct a breakthrough analysis, a solution containing tracer ions of known initial concentration is applied to a soil or substrate-filled column while the effluent that drains from the column is collected and analyzed to determine the concentration of the tracer. Relative concentration (RC) is determined by dividing $\mathrm{C}$ by $\mathrm{C}_{\mathrm{o}}$. The shape of the resulting BTC provides information about how the tracer was transported through the substrate. As the tracer solution enters the substrate, it interacts with the solution that is already in the pores at a "boundary" or "front." In an ideal system, this boundary moves evenly and unaltered through the substrate like a piston through a cylinder ("piston flow") with no mixing or dispersion of the applied tracer solution and the antecedent pore water (Jury and Horton, 2004). On the displacement of all the fluid in the pores [i.e., one pore volume (PV)], the theoretical piston reaches the other end of the column and is reflected in the BTC by a sudden increase in RC from 0 to 1 . In non-ideal systems, there typically exists a certain degree of interaction or mixing between the tracer solution and the antecedent pore water (through dispersion or diffusion), the extent of which is largely influenced by the physiochemical properties of the substrate. These interactions will affect the shape of the BTC. As the degree of interaction or mixing (and subsequent dispersion) increases, the slope of the BTC lessens (becomes less steep), and the transition from $\mathrm{RC}=0$ to 1 occurs across a larger effluent volume compared with the piston flow model, which is instantaneous.

The objective of this study was to develop BTCs for a pine bark-based substrate that is representative of the mid-Atlantic and southeastern U.S. nursery industries for the production of containerized ornamental crops. Breakthrough curves were generated under saturated and unsaturated conditions using tracer ions (mineral nutrients) that varied in their potential for chemical interaction with the substrate. The resulting BTCs were interpreted and used to describe solute transport, the behavior of reactive and non-reactive dissolved mineral nutrient ions, in a pine bark substrate.

\section{Materials and Methods}

Anion and cation solute transport experiments were conducted at the Virginia Tech Hampton Roads Agricultural Research and Extension Center (Virginia Beach, VA).

SubSTRATE PREPARATION AND ANALYSIS. A 9 pine bark (Carolina Bark Products, Seaboard, NC):1 concrete sand (Heard Aggregates, Waverly, VA) (by volume) substrate was amended with $1.8 \mathrm{~kg} \cdot \mathrm{m}^{-3}$ crushed dolomitic lime (Rockydale Quarries Corp., Roanoke, VA) and an equal amount of pelletized dolomitic lime (Kelly's Limestone, Kirksville, MO). To allow for chemical and moisture equilibration, the substrate was placed into 2.7-L (trade gallon) nursery containers (Myers Industries, Middlefield, $\mathrm{OH}$ ), 10 per experiment. In the cation transport experiment, 10 containers were placed on an outdoor gravel pad receiving daily 15-min overhead irrigation (12.7 mm $\cdot \mathrm{h}^{-1}$ ) for $1 \mathrm{month}$ (19 June to 17 July 2013). In the anion transport experiment, 10 containers were placed in a greenhouse for 2 weeks ( 7 to 20 Mar. 2014), where they were hand-watered on average every other day until leaching was observed. The anion transport experiment was conducted later in the year when temperatures were lower than when the cation transport experiment was conducted, necessitating substrate preparation in a greenhouse to allow for chemical equilibration under similar temperature conditions. The day before the solute transport experiments were conducted, the substrate for each experiment was pooled into one composite sample and allowed to equilibrate overnight in a sealed container to ensure an even moisture distribution before packing into columns. The same 
substrate was used in both the saturated and unsaturated treatment of the anion transport experiment. The substrate's particle size distribution (Table 1) was determined by way of a 5-min mechanical agitation [278 oscillations/min, 150 taps/ min (RX-29 Ro-Tap ${ }^{\circledR}$ shaker; W.S. Tyler industrial Group, Mentor, $\mathrm{OH})]$ with $\approx 100 \mathrm{~g}$ oven-dried substrate $(\mathrm{n}=3)$. Physical properties (Table 2 ) were determined using the North Carolina State University (NCSU) porometer procedure (Fonteno and Harden, 2003). Cation exchange capacity (CEC) was determined to be $( \pm \mathrm{SE}) 110.7 \pm 3.5 \mathrm{meq} \cdot \mathrm{L}^{-1}(\mathrm{n}=$ 3) using a method first described by Thorpe (1973) and modified by Altland et al. (2014).

COLUMN PREPARATION. Vertically oriented, acrylic columns $($ length $=30 \mathrm{~cm}$, i.d. $=7.75 \mathrm{~cm}$, o.d. $=8.9 \mathrm{~cm}$, volume $=1.415 \mathrm{~L})$ were packed with the previously described substrate using a modified version of the NCSU porometer procedure (Fonteno and Harden, 2003). The acrylic column was joined to a $15-\mathrm{cm}$ sealed-base section of polyvinyl chloride (PVC) pipe (i.d. and o.d. equal to the acrylic column) below and a $30-\mathrm{cm}$ section of PVC pipe above to create a $75-\mathrm{cm}$ packing apparatus. This apparatus was loosely filled to the top with substrate and dropped seven times from a height of $17.5 \mathrm{~cm}$ to achieve

Table 1. Particle size distribution of a screened substrate comprised of 9 pine bark:1 sand (by vol) for the cation and anion transport experiments. $^{\mathrm{z}}$

\begin{tabular}{lrr}
\hline & \multicolumn{1}{c}{ Anion expt. } & \multicolumn{1}{c}{ Cation expt. } \\
\cline { 2 - 3 } Size $(\mathrm{mm})$ & \multicolumn{1}{c}{$[$ mean \pm SE $(\%$ by wt)] } \\
\hline 6.3 & $20.5 \pm 1.5$ & $8.0 \pm 1.1$ \\
6.3 to 2 & $38.8 \pm 1.7$ & $27.6 \pm 1.1$ \\
2 to 0.71 & $33.7 \pm 1.8$ & $37.9 \pm 1.7$ \\
$<0.71$ & $26.5 \pm 0.8$
\end{tabular}

${ }^{\mathrm{z}}$ Values were attained by a 5-min mechanical agitation with oven-dried substrate $(\mathrm{n}=3)$.

Table 2. Physical properties of a substrate comprised of 9 pine bark: 1 sand (by vol) used in the cation and anion transport experiments, including bulk density $\left(\mathrm{D}_{\mathrm{b}}\right)$, total porosity $(\mathrm{TP})$, air space (AS), and container capacity (CC).

\begin{tabular}{lccccc}
\hline & $\mathrm{D}_{\mathrm{b}}$ & & $\mathrm{TP}$ & $\mathrm{AS}$ & $\mathrm{CC}$ \\
\cline { 2 - 2 } \cline { 5 - 6 } Expt. & {$\left[\mathrm{mean} \pm \mathrm{SE}\left(\mathrm{g} \cdot \mathrm{cm}^{-3}\right)\right]$} & & {$[$ mean $\pm \mathrm{SE}(\%$ by vol $)]$} \\
\hline \multicolumn{4}{c}{ Porometer analysis $^{\mathrm{z}}$} \\
Anion & $0.326 \pm 0.004$ & & $72.5 \pm 1.2$ & $26.5 \pm 1.4$ & $46.0 \pm 1.7$ \\
Cation & $0.288 \pm 0.003$ & & $81.5 \pm 0.9$ & $31.0 \pm 0.9$ & $50.5 \pm 0.4$
\end{tabular}

Measured in saturated columns $\mathrm{y}^{\mathrm{y}}$

Cation $\quad 0.324 \pm 0.004 \quad 77.5 \pm 2.6 \quad 29.4 \pm 1.7 \quad 48.1 \pm 1.5$

\section{Measured in unsaturated columns ${ }^{\mathrm{x}}$}

Cation $\quad 0.324 \pm 0.003 \quad-\quad \quad \quad-\quad 50.2 \pm 3.0$

${ }^{\mathrm{z}}$ Determined using the North Carolina State University (NCSU) porometer procedure; anion transport experiment $(n=3)$, cation transport experiment $(n=5)$.

${ }^{y}$ Determined using a modified version of the NCSU porometer procedure, where the porometer core and base were replaced by the acrylic column used in the anion and cation transport experiments replaced $(\mathrm{n}=3)$.

${ }^{x}$ Determined using the same procedure as the saturated columns. Determination of TP and AS requires the column to be at saturation and is therefore not calculable $(n=3)$. a consistent $D_{b}$ in the column between reps as determined by weighing the oven-dried substrate after use in the experiment. The top and bottom PVC sections of the packing apparatus were removed from the column and the substrate surface was leveled across each end of the column before installing the appropriate caps and fittings to be used in the saturated or unsaturated treatments (Fig. 1). A solution containing potassium nitrate $\left(\mathrm{KNO}_{3}\right)$ and monopotassium phosphate $\left(\mathrm{KH}_{2} \mathrm{PO}_{4}\right)$ was used in both the anion and cation transport experiments (Table 3).

Anion TRAnSPort. Anion transport was evaluated under saturated and unsaturated conditions. Packed columns were fitted with the appropriate PVC fittings for either the saturated or unsaturated treatment (Fig. 1). A circular piece (diameter $=$ $8.9 \mathrm{~cm}$ ) of standard, plastic window screen (Phifer, Tuscaloosa, AL) was cut to nest within each end-cap at each end of the column to prevent any particles from plugging the outlet and impeding the flow of water. For the saturated treatment, one barbed plastic fitting $(0.35 \mathrm{~cm}$ i.d.) was centered in each endcap to create an inlet and an outlet, through which solution could be applied to or drained from the column. At the inlet, the column was attached through $0.79-\mathrm{mm}$ PVC tubing (Tygon ${ }^{\circledR}$; Saint-Gobain North America, Valley Forge, PA) to a three-way valve and two glass 10-L Mariotte bottles, one containing DI water and the other containing the fertilizer solution. Mariotte bottles allow for water to flow through the column at a constant pressure that is dictated by the position of the lower end of the Mariotte bottles' air inlet tube, which creates a constant atmospheric reference pressure that does not change with the level of water in the bottle. The vertical orientation of the column creates a gradient in the tension along the column that ranges from $7.75 \mathrm{~cm}$ at the top of the column to $37.75 \mathrm{~cm}$ at the base (Fig. 1).

Once packed, the following sequential procedure was used on each column in the saturated treatment: 1) saturation: the column was slowly saturated from below by connecting the lower end of the column to the DI water source. Once saturated, water flow was stopped and the column was allowed to rest for $1 \mathrm{~h}$; 2) pore flush: DI water was passed through the column by adjusting the three-way valve to allow water to flow freely from the DI-containing Mariotte bottle and through the column (Fig. 1). Effluent was collected in 100-mL increments until effluent EC had reached a stable baseline of $10 \mu \mathrm{S} \cdot \mathrm{cm}^{-1}$ or less, as indicated by effluent analysis with a benchtop meter (Orion 4Star; Thermo Fisher Scientific, Waltham, MA) equipped with a DuraProbeTM 4-Electrode Conductivity Cell (Thermo Fisher Scientific); (3) tracer application: after the effluent EC was determined to be stable (from Step 2), the three-way valve was switched to the tracer solution and allowed to flow freely from the fertilizer-containing Mariotte bottle to the column. Effluent was collected in 150-mL increments and each sample collection time was recorded. This continued until $3 \mathrm{PV}(1 \mathrm{PV} \approx 1 \mathrm{~L})$ of effluent was collected to ensure that the majority of any latearriving solute after $1 \mathrm{PV}$ (relative to the aforementioned piston flow model) was reflected in the BTC. This resulted in 21 samples and 3.15 L of effluent per column; (4) DI application: without pause, the three-way valve was switched back to allow DI water to again flow from the DI-containing Mariotte bottle to the column. Three additional PVs of effluent were collected in $150-\mathrm{mL}$ increments (another 21 samples) with the sample collection times recorded to evaluate how the applied tracer ions were flushed from the system. The rate at which solution 


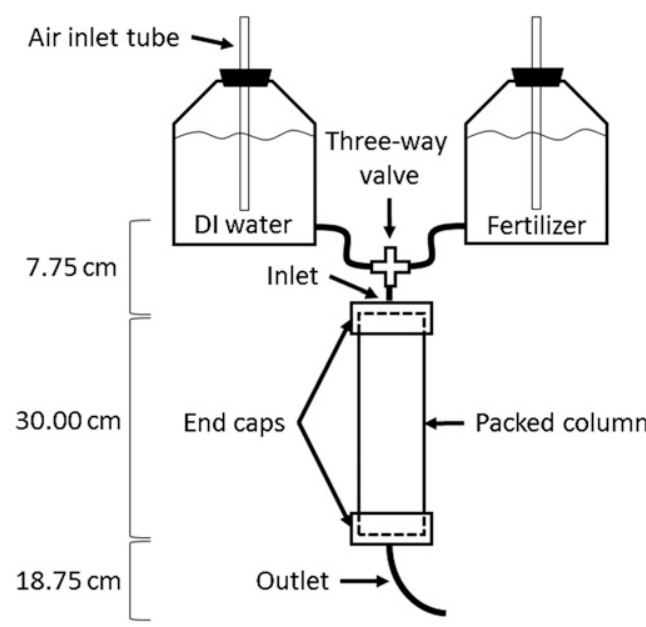

Unsaturated column

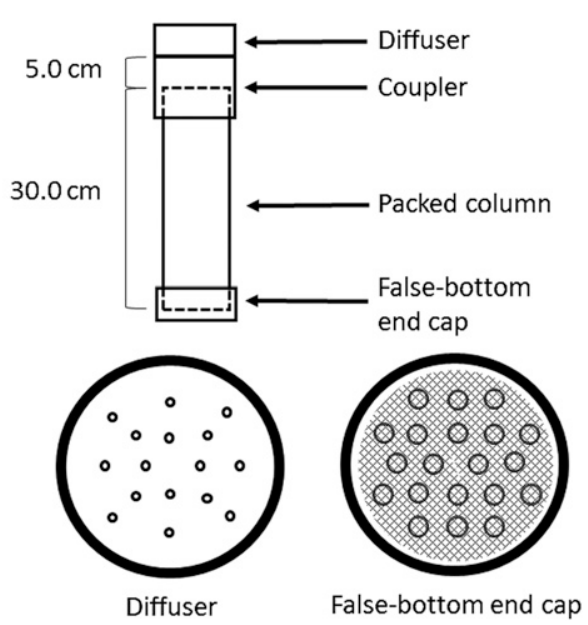

Fig. 1. Physical setup of the saturated and unsaturated column experiments for measuring ion transport in pine bark substrates.

Table 3. Fertilizer solution measured electrical conductivity (EC) and ion concentrations of nitrate $\left(\mathrm{NO}_{3}{ }^{-}\right)$, phosphate $\left(\mathrm{PO}_{4}{ }^{3-}\right)$, and potassium $\left(\mathrm{K}^{+}\right)$used in the cation and anion $(\mathrm{n}=6)$ transport experiments. ${ }^{\mathrm{z}}$

\begin{tabular}{lccccc}
\hline & $\mathrm{EC}$ & & $\mathrm{NO}_{3}$ & $\mathrm{PO}_{4}$ & $\mathrm{~K}$ \\
\cline { 2 - 2 } \cline { 5 - 6 } Expt. & {$\left[\mathrm{mean} \pm \mathrm{SE}\left(\mu \mathrm{S} \cdot \mathrm{cm}^{-1}\right)\right]$} & & \multicolumn{3}{c}{$\left[\mathrm{mean} \pm \mathrm{SE}\left(\mathrm{mg} \cdot \mathrm{L}^{-1}\right)\right]$} \\
\hline Anion & 345.2 & & 95.4 & 118.0 & 106.1 \\
Cation & 333.0 & & 106.0 & 105.1 & 105.0
\end{tabular}

${ }^{\mathrm{z}}$ Fertilizer ions were derived from potassium nitrate $\left(\mathrm{KNO}_{3}\right)$ and monopotassium phosphate $\left(\mathrm{KH}_{2} \mathrm{PO}_{4}\right)$.

moved through the column throughout Steps 3 and 4 was determined to be $2.5 \mathrm{~mL} \cdot \mathrm{s}^{-1} \pm 0.1$.

After the desired effluent volume had been collected, the application of DI water was discontinued and the column was allowed to drain for $1 \mathrm{~h}$, which allowed for the measurement of container capacity [CC (percent of the substrate volume comprised of water after drainage from saturation)]. At this point, the column was also weighed, emptied, and the substrate placed in an oven to dry until weight was constant. The volume of water that drained from saturation to $\mathrm{CC}$ was used to determine the air space [AS (percent of the substrate volume comprised of air at CC)]. The difference in substrate weight at $\mathrm{CC}$ and after oven-drying was used to determine the volume of water held in the substrate at CC. Air space and CC were summed to determine TP (sum of void space occupied by air and water). Bulk density was calculated by dividing the weight of the dry substrate by the container volume. These physical properties are reported in Table 2 alongside those determined by porometer analysis. The aforementioned experimental procedure (Steps 1 to 4) and post-experiment assessment of substrate physical properties were repeated for each of three replicates using a newly packed column.

In the unsaturated treatment, the number of $150-\mathrm{mL}$ effluent samples (21 during tracer application and another 21 during DI application) and total effluent volume collected (combined 6.3 L) were the same as the saturated treatment. Instead of connecting to Mariotte bottles for the application of fertilizer solution and DI water, the lower end of the column was fitted

with a false-bottom PVC flat-cap with 20 evenly distributed, $8-\mathrm{mm}$ holes (Fig. 1). An identically sized piece of mesh screen was nested in this cap to minimize the loss of substrate. The saturation procedure (Step 1) was modified by placing the packed column in a 19-L bucket, which was slowly filled with DI water. As the bucket filled, DI water entered the column through the lower, false-bottom flat-cap until the water level reached the substrate surface, at which point it was allowed to rest and saturated for $1 \mathrm{~h}$, after which the column was removed from the bucket and was allowed to drain for $15 \mathrm{~min}$ before initiating the DI flush (Step 2). The upper end of the column was fitted with a PVC coupler to support a diffuser $5 \mathrm{~cm}$ above the substrate surface (Fig. 1). The diffuser was a modified PVC flat-cap that contained 16 evenly distributed, 2-mm holes that facilitated an even distribution of solution over the substrate surface. The tracer solution (Step 3) or DI water (Step 4) was poured, in $75-\mathrm{mL}$ increments, every $2 \mathrm{~min}$ into the diffuser until the desired effluent volume was collected for either the respective tracer or DI application steps. On finishing Step 4, the substrate was allowed to drain for $1 \mathrm{~h}$ and was processed in the same manner as the saturated columns. However, because this treatment was unsaturated, determination of TP and AS was not possible.

The anion transport experiment was conducted over a 3-d period, where one saturated and unsaturated replication was conducted each day ( $\mathrm{n}=3$ for each treatment). The fertilizercontaining Mariotte bottle provided a sufficient volume of tracer solution for one saturated and unsaturated replication. The fertilizercontaining Mariotte bottle was replenished from a stock solution after one saturated and unsaturated replication had been completed.

Cation transport. Cation transport was evaluated under saturated conditions and followed the same procedure (Steps 1 to 4) used in the saturated treatment of the anion transport experiment with the following exceptions. In Step 2 (pore flush), a pH/EC meter (HI 9813-6; Hanna Instruments, Woonsocket, RI) was used to measure EC and $\mathrm{pH}$. In Step 3 (tracer application), two PVs of effluent were collected. The sequence was conducted for three repetitions using a newly packed column for each treatment. One Mariotte bottle provided a sufficient volume of tracer solution for all replications, and therefore, one batch of tracer solution was used. The average rate at which solution moved through the column was determined to be $( \pm \mathrm{SE}) 4.5 \pm 0.9 \mathrm{~mL} \cdot \mathrm{s}^{-1}$ during Steps 3 and 4 .

Data ANalysis. A $10-\mathrm{mL}$ aliquot of each effluent sample was collected and filtered $(0.2-\mu \mathrm{m} 30-\mathrm{mm}$ syringe filter; Thermo Fisher Scientific) for ion analysis before measuring $\mathrm{EC}$ and $\mathrm{pH}$ of individual effluent samples. All analyses were conducted at room temperature $\left(\approx 25^{\circ} \mathrm{C}\right)$. Filtered samples were refrigerated before immediate analysis or stored at $-18^{\circ} \mathrm{C}$ if analysis could not occur within $48 \mathrm{~h}$. Nitrate, phosphate $\left(\mathrm{PO}_{4}{ }^{3-}\right), \mathrm{K}^{+}$, magnesium, and calcium concentrations were analyzed for the respective experiment using an ion chromatography system (ICS-1600; Thermo Fisher Scientific) equipped with a $4 \times 250$-mm (i.d. $\times$ length) 
anion-exchange column (AS22; Thermo Fisher Scientific) at $35^{\circ} \mathrm{C}$, a $4 \times 25-\mathrm{mm}$ cation-exchange column $(\mathrm{CS} 12 \mathrm{~A}$; Thermo Fisher Scientific) at $35^{\circ} \mathrm{C}$, and an autosampler (AS-AP; Thermo Fisher Scientific) on a $25-\mu \mathrm{L}$ sample loop driven by an isocratic pump.

In the anion transport experiment, EC readings and ion concentrations were converted to $\mathrm{RCs}$ by dividing $\mathrm{C}$ by $\mathrm{C}_{\mathrm{o}}$ for the parameter of interest (EC or ion concentration) and are presented as BTCs along with SEs. Effluent $\mathrm{pH}$ was measured at the onset of tracer application (Step 3), at the transition between tracer and DI application (between Steps 3 and 4), and at the end of DI application (Step 4). The fertilizer (Step 3) and DI (Step 4) application steps of each BTC in the anion transport experiment were analyzed separately using logistic regression Eq. [1]:

$$
y=\frac{1}{1+\operatorname{Exp}(-a(x-b))}
$$

where $a=$ rate of change and $b=$ inflection point $(\mathrm{RC}=0.5)$, assuming that $\mathrm{RC}$ will range from 0 to 1 . Mean and SE of the inflection point and rate of change estimates were reported. The resultant $\mathrm{EC}, \mathrm{NO}_{3}{ }^{-}$, and $\mathrm{PO}_{4}{ }^{3-}$ curves from the logistic regression analysis of the anion transport experiment were subject to a sums of squares reduction test $(\alpha=0.05)$ to evaluate the difference between saturated and unsaturated conditions during tracer and DI application (analyzed separately). The sums of squares reduction test was conducted using $\mathrm{SAS}^{\circledR}$ (Version 9.3; SAS Institute, Cary, NC).

In the cation transport experiment, $\mathrm{EC}$ readings and ion concentrations were also converted to RCs by dividing $\mathrm{C}$ by $\mathrm{C}_{\mathrm{o}}$ for the parameter of interest (EC or ion concentration) and are presented as BTCs along with SES. Furthermore, the difference in equivalent charge (milliequivalents) of $\mathrm{NO}_{3}{ }^{-}$and $\mathrm{K}^{+}$in each effluent sample was used as an indicator of the amount of $\mathrm{K}^{+}$ retained in the substrate at each cumulative effluent volume, because $\mathrm{NO}_{3}{ }^{-}$and $\mathrm{K}^{+}$were applied at the same concentration. All data were processed using JMP ${ }^{\circledR}$ Pro (Version 10.0.2; SAS Institute).

\section{Results}

Anion Transport. Solute transport processes were different between unsaturated and saturated conditions as indicated by the shape of the BTCs (Fig. 2) and their estimated parameters (Table 4). Tracer breakthrough occurred earlier (i.e., with less effluent volume) during unsaturated conditions for the application of both the tracer solution and DI water [parameter $b$ (Table 4)]. During the application of tracer solution (Step 3), the inflection point (parameter $b$ ), or center of the BTC where $\mathrm{RC}=0.5$, occurred with 229, 236, and $209 \mathrm{~mL}$ less effluent under unsaturated than saturated conditions for the $\mathrm{EC}, \mathrm{NO}_{3}{ }^{-}$, and $\mathrm{PO}_{4}{ }^{3-}$ BTCs, respectively (Table 4). Similarly, when the tracer solution was flushed from the substrate pores (Step 4), the inflection point occurred with 198, 200, and $174 \mathrm{~mL}$ less effluent under unsaturated conditions for the $\mathrm{EC}, \mathrm{NO}_{3}{ }^{-}$, and $\mathrm{PO}_{4}{ }^{3-}$ BTCs, respectively. Similar effects were seen for the BTC rate of changes (parameter $a$ ), where the absolute value of the parameter was of greater magnitude for the unsaturated treatment for each tracer during both the tracer and DI application steps (Table 4). During the application of DI water, the curves move in the opposite direction [Fig. 2 (RC moves from 1 to 0$)$ ] and subsequently, parameter $a$ is negative. Throughout Steps 3 and 4, effluent $\mathrm{pH}$ was initially ( $\pm \mathrm{SE})$

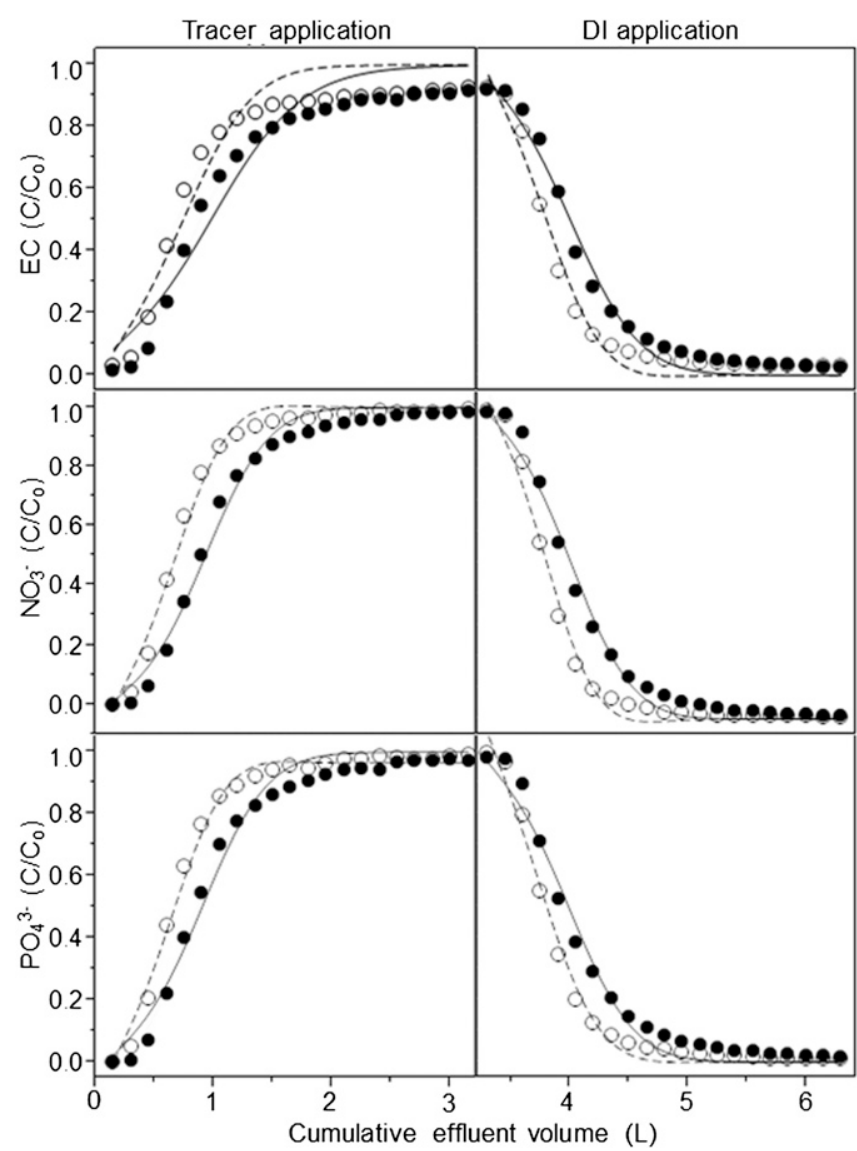

Fig. 2. Anion transport experiment breakthrough curves showing electrical conductivity $(\mathrm{EC})$, nitrate $\left(\mathrm{NO}_{3}{ }^{-}\right)$, and phosphate $\left(\mathrm{PO}_{4}{ }^{3-}\right)$ relative effluent concentration $\left(\mathrm{C} / \mathrm{C}_{\mathrm{o}}\right.$, where $\mathrm{C}$ and $\mathrm{C}_{\mathrm{o}}=$ effluent and input solution concentration, respectively) during the application of a fertilizer solution $(\approx 100$ $\mathrm{mg} \cdot \mathrm{L}^{-1} \mathrm{NO}_{3}{ }^{-}$and $\mathrm{PO}_{4}{ }^{3-}$ each) and deionized (DI) water to a pine-bark substrate under $(\bullet)$ saturated and $(\mathrm{O})$ unsaturated conditions. The vertical line indicates when the input solution changed from fertilizer to DI water. Parameters for the (---) unsaturated and (-) saturated regression lines are reported in Table 4.

$6.51 \pm 0.08$ at the onset of tracer application, $5.45 \pm 0.04$ at the transition between tracer and DI application, and $6.62 \pm 0.06$ at the end of DI application.

Cation transport. The $\mathrm{NO}_{3}{ }^{-}$BTC in Figure 3 exhibited a curvilinear shape that was similar to those shown in the anion transport experiment (Fig. 2) and reached nearly full concentration $\left(\mathrm{C} / \mathrm{C}_{\mathrm{o}}=0.9\right)$ after $2 \mathrm{~L}$ of effluent had been collected. In contrast, the $\mathrm{K}^{+} \mathrm{BTC}$ in Figure 3 exhibited a more linear increase in effluent $\mathrm{K}^{+}$concentration that only reached $\mathrm{C} / \mathrm{C}_{\mathrm{o}}=$ 0.5 after $2 \mathrm{~L}$ of effluent had been collected. The shape of these curves revealed that during application of tracers (Step 3), the movement of an infiltrating cation $\left(\mathrm{K}^{+}\right)$through the column was retarded, relative to the movement of the anion, $\mathrm{NO}_{3}{ }^{-}$(Fig. 3A). Throughout the experiment, a total of $204.8 \mathrm{mg}$ of $\mathrm{K}^{+}$was applied to each column. Of that total $( \pm \mathrm{SE}), 129.1 \pm 4.0 \mathrm{mg}(3.3 \pm$ $0.1 \mathrm{meq})$ was leached, leaving $75.7 \pm 4.0 \mathrm{mg}(1.9 \pm 0.1 \mathrm{meq})$, or $37.0 \%$ of applied $\mathrm{K}^{+}$retained by the substrate. This quantity of retained $\mathrm{K}^{+}$represents $1.2 \%$ of the available CEC for this substrate. Furthermore $( \pm \mathrm{SE}) 15.6 \pm 0.6 \mathrm{mg} \mathrm{Ca}^{2+}$ and $7.8 \pm$ $0.5 \mathrm{mg} \mathrm{Mg}^{2+}$ were leached throughout the experiment. This represented a combined $1.4 \pm 0.1$ meq of $\mathrm{Ca}^{2+}$ and $\mathrm{Mg}^{2+}$ and accounted for $43.1 \%$ of the retained $\mathrm{K}^{+}$. 
Table 4. Parameter estimates $( \pm \mathrm{SE})$ for the electrical conductivity $(\mathrm{EC})$, nitrate $\left(\mathrm{NO}_{3}^{-}\right)$, and phosphate $\left(\mathrm{PO}_{4}^{3-}\right)$ breakthrough curves from the anion transport experiment, developed by applying a tracer solution [derived from potassium nitrate $\left(\mathrm{KNO}_{3}\right)$ and monopotassium phosphate $\left(\mathrm{KH}_{2} \mathrm{PO}_{4}\right)$ and deionized (DI) water] to a column filled with a 9 pine bark: 1 sand (by vol.) substrate under saturated and unsaturated conditions.

\begin{tabular}{|c|c|c|c|c|c|c|c|}
\hline \multirow[b]{2}{*}{ Tracer } & \multirow[b]{2}{*}{ Condition } & \multicolumn{3}{|c|}{ Tracer application $^{z}$} & \multicolumn{3}{|c|}{ DI water application $^{z}$} \\
\hline & & $a$ & $b$ & $R^{2}$ & $a$ & $b$ & $R^{2}$ \\
\hline \multirow[t]{2}{*}{$\mathrm{EC}$} & Saturated & $0.0027 \pm 0.0002$ & $970.5 \pm 24.9$ & 0.93 & $-0.0038 \pm 0.0002$ & $852.4 \pm 37.8$ & 0.98 \\
\hline & Unsaturated & $0.0038 \pm 0.0001$ & $741.3 \pm 2.0$ & 0.92 & $-0.0054 \pm 0.0001$ & $654.5 \pm 24.1$ & 0.98 \\
\hline $\mathrm{NO}_{3}^{-}$ & Saturated & $0.0044 \pm 0.0004$ & $918.6 \pm 51.6$ & 0.97 & $-0.0045 \pm 0.0003$ & $857.2 \pm 43.3$ & 0.98 \\
\hline \multirow[t]{3}{*}{$\mathrm{PO}_{4}^{3-}$} & Saturated & $0.0042 \pm 0.0003$ & $890.4 \pm 57.2$ & 0.96 & $-0.0042 \pm 0.0003$ & $836.7 \pm 45.4$ & 0.98 \\
\hline & Unsaturated & $0.0054 \pm 0.0001$ & $681.0 \pm 3.5$ & 0.99 & $-0.0061 \pm 0.0001$ & $662.8 \pm 18.9$ & 0.99 \\
\hline & $P$ value & & & $<0.00001$ & & & $<0.00001$ \\
\hline
\end{tabular}

${ }^{\mathrm{z}} \mathrm{EC}, \mathrm{NO}_{3}^{-}$, and $\mathrm{PO}_{4}^{3-}$ tracer data were fit with the logistic regression model $\mathrm{y}=1 /\{1+\mathrm{Exp}[-a(\mathrm{x}-b)]\}$, where $\mathrm{y}$ is the relative effluent $\mathrm{EC}$ or tracer concentration $\left(\mathrm{RC}=\mathrm{C} / \mathrm{C}_{\mathrm{o}}\right.$, where $\mathrm{C}=$ effluent $\mathrm{EC}$ or tracer concentration and $\mathrm{C}_{\mathrm{o}}=$ initial $\mathrm{EC}$ or tracer concentration), $\mathrm{x}$ is the cumulative effluent volume, $a$ is the rate of change (unitless), and $b$ is the inflection point [milliliters (value of $\mathrm{x}$ when $\mathrm{RC}=0.5$ )].

${ }^{\mathrm{y}}$ Differences between the curves for saturated and unsaturated conditions were evaluated using a sums of squares reduction test.

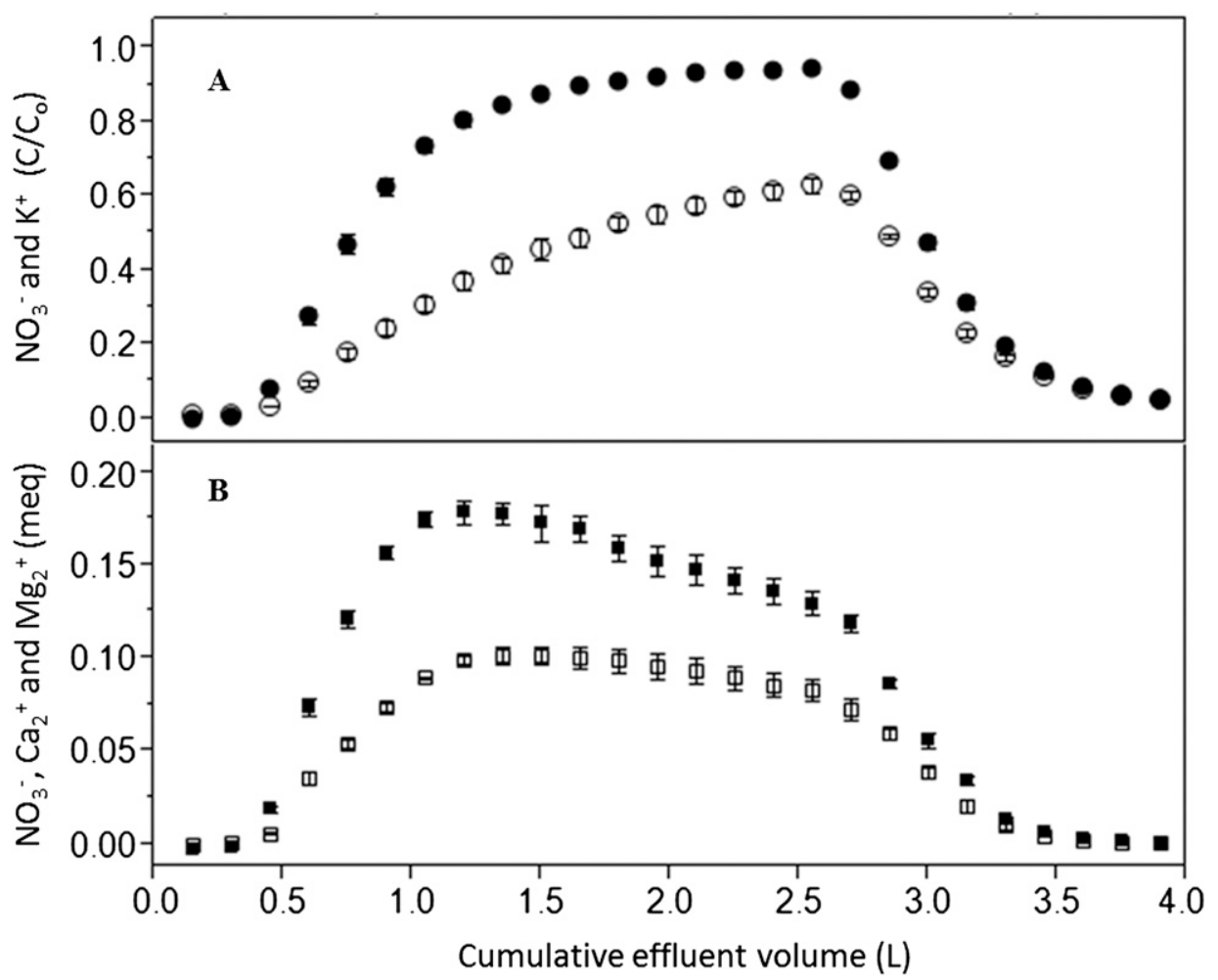

Fig. 3. Cation transport experiment results showing $(\mathbf{A})$ ion breakthrough curves for $(\bullet)$ nitrate $\left(\mathrm{NO}_{3}-\right)$ and $(\mathrm{O})$ potassium $\left(\mathrm{K}^{+}\right)$relative effluent concentrations $\left(\mathrm{C} / \mathrm{C}_{\mathrm{o}}\right.$; where $\mathrm{C}$ and $\mathrm{C}_{\mathrm{o}}=$ effluent and input solution concentration, respectively) and (B) exchanged cations ( $\square$ ) [sum of calcium $\left(\mathrm{Ca}^{2+}\right)$, magnesium $\left.\left(\mathrm{Mg}^{2+}\right)\right]$ equivalent charge (milliequivalents) in effluent and $(\mathbf{\square})$ approximate meq potassium $\left(\mathrm{K}^{+}\right)$retained $\left(\mathrm{meq} \mathrm{NO}_{3}{ }^{-}\right.$ - meq $\left.\mathrm{K}^{+}\right)$. Error bars are SE $(\mathrm{n}=3)$. From 0 to $2 \mathrm{~L}$ cumulative effluent volume, a tracer solution was applied. From 2 to $4 \mathrm{~L}$ cumulative effluent volume, deionized water was applied.

\section{Discussion}

Solute movement was slower under saturated conditions compared with unsaturated, which was likely the result of the velocity of water through pores of variable size. The movement of water is affected by pore or channel size and the degree to which they are interconnected $(\mathrm{Ma}$ and Selim, 1997). Drzal et al. (1999) demonstrated that pine bark substrates contain many pore sizes that range from macropores (greater than $416 \mu \mathrm{m}$ ) to ultramicropores (less than $0.2 \mu \mathrm{m}$ ). With this in mind, the preferential flow of water through macropores (less restricted) over micropores (more restricted) may lead to a portion of the applied tracer solution reaching the base of the column more quickly via transport through macropores. Furthermore, within a saturated pore, solution will flow at a higher velocity in the center of the pore than near the particle surfaces where physical and chemical interactions between water and the particle surfaces may restrict flow (Hillel, 2004). Consequently, a range of pore water velocities exists within a pore (driven by the solutions proximity to the particle surface) and within the bulk substrate (driven by the pore or channel size distribution). This range of pore sizes and pore water velocities will allow for a portion of the applied tracer solution to arrive at the opposite end of the column earlier (via travel through the center of pores) than others (slower transport near particulate surfaces); hence, complete solute breakthrough ( $\mathrm{RC}$ changes from 0 to 1 or 1 to 0 ) is a gradual process.

Under unsaturated conditions, the column inherently contains less water than under saturated conditions. As a result, there is less water to be displaced as the tracer or DI water is applied, possibly explaining the leftward shift of the inflection points (parameter $b$ in Table 4 ) in the unsaturated BTCs relative 
to the saturated BTCs. However, the steeper slopes (parameter $a$ in Table 4) observed in the unsaturated BTCs are more likely a result of the pore water velocity distributions. The previously discussed distribution of pore water velocities under saturated conditions would still occur under unsaturated conditions as a result of flow through macro- and micropores. However, because water flows predominantly along particulate surfaces in unsaturated conditions, the development of very fast pore water velocities found in the center of saturated macropores is presumably less prone to develop (Hillel, 2004). Therefore, the range of pore water velocities that occur during unsaturated conditions would be smaller than saturated conditions. This smaller range of pore water velocities may lead to a more even boundary between the applied tracer solution and the old pore water that allows the transition from $\mathrm{RC}=0$ to 1 to occur more quickly (over a smaller portion of the Fig. $2 \mathrm{x}$-axis or effluent volume), a trend that is reflected by the early breakthrough observed in the unsaturated treatment of the anion transport experiment.

During active, saturated solute transport in the cation transport experiment, the movement of an infiltrating cation $\left(\mathrm{K}^{+}\right)$ through the substrate was different from the movement of anions. Potassium breakthrough was a more gradual process and may have contributed to the reduced slope or rate of change (parameter $a$ in Table 4) for the EC BTCs as compared with that of $\mathrm{NO}_{3}{ }^{-}$and $\mathrm{PO}_{4}{ }^{3-}$ in the anion transport experiment. Because $\mathrm{EC}$ is a measure of the bulk ions in the solution, the EC BTCs are reflective of both cation and anion transport. Therefore, the relatively lower slopes or rate of change in the EC BTCs are likely a result of the slower movement of $\mathrm{K}^{+}$through the substrate compared with $\mathrm{NO}_{3}{ }^{-}$(Fig. 3A). In Figure 2, effluent $\mathrm{EC}$ does not reach full tracer $\mathrm{EC}(\mathrm{RC}=1)$ and is also a likely result of the reduced effluent $\mathrm{K}^{+}$concentrations. This may explain the slight deviation of the EC data from the logistic model in the upper portion of the tracer application EC BTC, where the model assumes $\mathrm{RC}$ will reach 1 .

The chemical interaction between $\mathrm{K}^{+}$and pine bark cation exchange sites reduced the total load of $\mathrm{K}^{+}$that was leached from the substrate. During this process, other cations $\left(\mathrm{Ca}^{2+}\right.$ and $\mathrm{Mg}^{2+}$ ) were displaced from these exchange sites. The meq of $\mathrm{K}^{+}$that was calculated to have been retained by the substrate throughout the experiment (Fig. 3B) followed a similar trend to the combined meq of $\mathrm{Ca}^{2+}$ and $\mathrm{Mg}^{2+}$ that was leached. The magnitude of the $\mathrm{Ca}^{2+}$ and $\mathrm{Mg}^{2+}$ curve is less than the retained $\mathrm{K}^{+}$curve and leached $\mathrm{Ca}^{2+}$ and $\mathrm{Mg}^{2+}$ only accounted for $43.1 \%$ of retained $\mathrm{K}^{+}$suggests that other, unmeasured cations were exchanged by $\mathrm{K}^{+}$. Pokorny (1979) reported the presence of boron, copper, iron, manganese, and zinc in pine bark, which may have also interacted with $\mathrm{K}^{+}$on bark exchange sites.

The amount of retained $\mathrm{K}^{+}$accounted for only $1.2 \%$ of the available CEC of the substrate. This finding alone warrants further research into a functional quantification of the cation exchange that occurs under varying conditions (i.e., ion species, residence times, $\mathrm{pH}$, and moisture content) that are likely to occur in a production scenario such as during fertilizer application or between irrigation events. Daniels and Wright (1988) found surprisingly few differences between the CEC of various pine bark particle size fractions and hypothesized that the internal porosity of pine bark may account for a significant portion of the overall CEC. Mohammadi et al. (2009) discussed an immobile fraction of the soil solution that, when accounted for in prediction models, allowed for a fairly accurate prediction of solute breakthrough. Pokorny (1987) found that the internal porosity of pine bark accounted for $42.7 \%$ to $44.0 \%$ of its total volume. However, the quantity and mobility of the internal pore solution of pine bark substrates and the accessibility of those internal pores to the ions in a solution that is freely flowing through the substrate are in question.

The range of measured effluent $\mathrm{pH}$ values in the anion transport experiment reflects the $\mathrm{pH}$ of the two different solutions, DI water (neutral $\mathrm{pH}$ ) and the tracer solution (low $\mathrm{pH}$ ), that were infiltrated through the substrate pores. Had this been measured under static conditions, rather than active solute transport, it is possible that the substrate may be able to buffer these $\mathrm{pH}$ changes as described by Altland et al. (2014). An unexpected observation while conducting both the cation and anion transport experiment was that during the pre-experiment DI flush (Step 1), the effluent was consistently cloudy and had a light brown color that became clear when fertilizer solution was applied (Step 2). It became cloudy again when DI water was re-applied in Step 3. A similar effect was observed in previous CEC studies (Daniels and Wright, 1988), where the washing of bark with distilled water after ion displacement produced a cloudy solution. Their observations and ours may suggest an interaction between soluble organic materials and applied fertilizer ions. It is possible that when the substrate pores are comprised mainly of DI water (low ionic strength and high $\mathrm{pH}$ ), soluble organic materials are disassociated from the bark and into the pore solution. Conversely, when the pore solution is comprised mainly of fertilizer solution (high ionic strength and low $\mathrm{pH}$ ), the extraction of soluble organic materials is restricted.

\section{Conclusion}

The behavior of individual ion species during active solute transport through a pine bark substrate differed with ion species and the method of analysis (saturated or unsaturated pores). Anions were passed through the substrate relatively unobstructed. In contrast, cations were retained by the pine bark to an extent that constituted a surprisingly small portion of the substrates' measured CEC. The findings discussed here provide insight into how individual ions move through and leach from a pine bark substrate during irrigation events and how the leached nutrient load may be affected by the volume of water that is drained from the substrate. Several factors appear to be occurring that affect the movement of solutes through pine bark substrates, including the dispersion of tracer ions through macropore (relatively unrestricted) and micropore (relatively restricted) flow, diffusion of the tracer ions across the concentration gradients within the substrate, and chemical interaction or exchange between tracers and bark particle exchange sites. The approach used in this study may be used in horticultural research to better understand how nutrients move through and leach from soilless substrates during irrigation. Expanding this knowledge base may lead to the refinement of crop models and production practices that improve nutrient and water use efficiency in container nurseries.

\section{Literature Cited}

Adams, C., J. Frantz, and B. Bugbee. 2013. Macro- and micronutrientrelease characteristics of three polymer-coated fertilizers: Theory and measurements. J. Plant Nutr. Soil Sci. 176:76-88. 
Alam, M.Z., C. Chong, J. Llewellyn, and G.P. Lumis. 2009. Evaluating fertilization and water practices to minimize $\mathrm{NO}_{3}-\mathrm{N}$ leachate from container-grown forsythia. HortScience 44:1833-1837.

Altland, J.E., J.C. Locke, and C.R. Krause. 2014. Influence of pine bark particle size and $\mathrm{pH}$ on cation exchange capacity. HortTechnology 24:554-559.

Beven, K. and P. Germann. 2013. Macropores and water flow in soils revisited. Water Resour. Res. 49:3071-3092.

Bilderback, T., C. Boyer, M. Chappell, G. Fain, D. Fare, C. Gilliam, B.E. Jackson, J. Lea-Cox, A.V. LeBude, A. Niemiera, J. Owen, J. Ruter, K. Tilt, S. Warren, S. White, T. Whitewell, R. Wright, and T. Yeager. 2013. Best management practices: Guide for producing nursery crops. Southern Nursery Assn., Acworth, GA.

Brown, E.F. and F.A. Pokorny. 1977. Potassium distribution and retention in pine-bark and sand media. HortScience 12:343-344.

Cabrera, R.I. 1997. Comparative evaluation of nitrogen release patterns from controlled-release fertilizers by nitrogen leaching analysis. HortScience 32:669-673.

Colangelo, D.J. and M.H. Brand. 2001. Nitrate leaching beneath a containerized nursery crop receiving trickle or overhead irrigation. J. Environ. Qual. 30:1564-1574.

Cox, D.A. 1993. Reducing nitrogen leaching-losses from containerized plants-The effectiveness of controlled-release fertilizers. J. Plant Nutr. 16:533-545.

Daniels, W.L. and R.D. Wright. 1988. Cation-exchange properties of pine-bark growing media as influenced by $\mathrm{pH}$, particle-size, and cation species. J. Amer. Soc. Hort. Sci. 113:557-560.

Drzal, M.S., W.C. Fonteno, and D.K. Cassel. 1999. Pore fraction analysis: A new tool for substrate testing. Acta Hort. 481:43-54.

Fonteno, W.C. and C.T. Harden. 2003. Procedures for determining physical properties of horticultural substrates using the NCSU porometer. 15 May 2013. <http://www.ncsu.edu/project/hortsublab/ pdf/porometer_manual.pdf $>$.

Foster, W.J., R.D. Wright, M.M. Alley, and T.H. Yeager. 1983. Ammonium adsorption on a pine-bark growing medium. J. Amer. Soc. Hort. Sci. 108:548-551.
Hillel, D. 2004. Introduction to environmental soil physics. Elsevier Academic Press, Amsterdam, The Netherlands/Boston, MA.

Hoskins, T.C. 2014. Water and nutrient transport dynamics during the irrigation of containerized nursery crops. MS thesis, Virginia Tech, Blacksburg, VA.

Husby, C.E., A.X. Niemiera, J.R. Harris, and R.D. Wright. 2003. Influence of diurnal temperature on nutrient release patterns of three polymer-coated fertilizers. HortScience 38:387-389.

Jury, W.E. and R. Horton. 2004. Soil physics. 6th Ed. Wiley, Hoboken, NJ.

Keller, A.A., S. Sirivithayapakorn, and C.V. Chrysikopoulos. 2004. Early breakthrough of colloids and bacteriophage MS2 in a watersaturated sand column. Water Resour. Res. 40:W08304.

Liu, Q., V. Lazouskaya, Q.X. He, and Y. Jin. 2010. Effect of particle shape on colloid retention and release in saturated porous media. J. Environ. Qual. 39:500-508.

Ma, L.N. and H.M. Selim. 1997. Physical nonequilibrium modeling approaches to solute transport in soils. Adv. Agron. 58:95-150.

Majsztrik, J.C. 2011. Modeling nitrogen, phosphorus and water dynamics in greenhouse and nursery production systems. PhD diss., Univ. of Maryland, College Park, MD.

Mohammadi, M.H., M.R. Neishabouri, and H. Rafahi. 2009. Predicting the solute breakthrough curve from soil hydraulic properties. Soil Sci. 174:165-173.

Newman, J.P., J.P. Albano, D.J. Merhaut, and E.K. Blythe. 2006. Nutrient release from controlled-release fertilizers in a neutral-pH substrate in an outdoor environment: I. Leachate electrical conductivity, $\mathrm{pH}$, and nitrogen, phosphorus, and potassium concentrations. HortScience 41:1674-1682.

Pokorny, F.A. 1979. Pine-bark container media-An overview. Combined Proc. Intl. Plant Prop. Soc. 29:484-495.

Pokorny, F.A. 1987. Available water and root development within the micropores of pine-bark particles. J. Environ. Hort. 5:89-92.

Thorpe, V.A. 1973. Collaborative study of the cation exchange capacity of peat materials. J. Assoc. Off. Anal. Chem. 56:154157. 